\title{
Use of high activity enzyme preparations in neat organic solvents for organic synthesis
}

\author{
Munishwar Nath Gupta ${ }^{1 *}$, Joyeeta Mukherjee ${ }^{2}$ and Deepika Malhotra ${ }^{1}$ \\ *Correspondence: munishwar48@yahoo.co.uk \\ 'Department of Biochemical Engineering and Biotechnology, Indian Institute of Technology Delhi, Hauz Khas, \\ New Delhi 110016, India. \\ ${ }^{2}$ Department of Chemistry, Indian Institute of Technology Delhi, Hauz Khas, New Delhi 110016, India.
}

\begin{abstract}
The use of enzymes in nearly anhydrous organic solvents generally results in low initial rates/percentage conversions. The current review focuses on some biocatalyst designs like immobilization on nanomaterials, enzyme precipitated and rinsed with organic solvents (EPROS), crosslinked enzyme crystals (CLEC), crosslinked enzyme aggregates (CLEA), protein coated microcrystals (PCMC) and crosslinked protein coated microcrystals (CLPCMC) which show much better catalytic efficiency in such media as compared to other kinds of biocatalyst preparations. The basic methodology and principle behind these efficient designs are described. The relatively recent results on catalytic promiscuity as seen in low water media have also been covered. It is hoped that this will further encourage wider applications of enzymes in neat organic solvents in organic synthesis.
\end{abstract}

Keywords: Transesterification reactions, aldol condensation, kinetic resolution, enantioselective reactions, regioselectivity, nanobiocatalysts, enzyme catalysis in low water media, enzyme promiscuity

\section{Introduction}

Use of enzymes in nearly anhydrous organic solvents has opened up fresh opportunities for their use in organic synthesis. An excellent review by Lee and Dordick (2002) [1] summarized the growing evidence by 1990s that the catalytic rates obtained by using enzymes in such media are lower by several orders of magnitude as compared to ones obtained in water. One striking example given in that review concerns regioselective acylation of paclitaxel (an anticancer drug) which was not possible till efforts were repeated with a "salt activated" preparation of thermolysin. It is worrisome that bulk of the papers using enzymes in low water media does not pay attention to this issue and often poor initial rates/conversions are reported. Lyophilization or freeze drying is often used for preparing enzymes for use in low water media or lyophilized/spray dried enzyme powders "straight from the vendor" are used. This has sometimes discouraged organic chemists from replacing chemical catalysts with enzymes.

This review primarily focuses on general principles underlying efforts which have resulted in enzyme formulations which show much higher catalytic activity in low water containing organic solvents. The applications of these high activity preparations in organic synthesis are also described. It is hoped that awareness of these results would induce wider and more successful applications of enzymes in low water media in the area of organic synthesis. This review is limited to nearly anhydrous organic solvents as the reaction medium. Other low water media are reverse micelles and ionic liquids $[2,3]$.

\section{Review}

Some fundamental concepts in non aqueous enzymology Enzymes in low water media still require some small amount of water (believed to be less than the monolayer surrounding the enzyme molecules). The phrase "nearly anhydrous" often used to describe the low water media relates to this fact. For optimum activity in such media, the amount of water required to be added depends upon multiple factors as the added water gets distributed over multiple phases (organic solvent, support material for immobilized enzymes, vapour phase/air in the reaction vessel, substrates, products etc). Hence it is more prudent to talk in terms of $a_{w^{\prime}}$, however this is not so useful in polar solvents. This is a rather complex issue which has been discussed at great length elsewhere [4]. The general picture is that hydrophobic solvents as media provide better initial rates as hydrophilic organic solvents strip off the essential water layer from the enzyme molecules. Log $P$ is considered as the best parameter for organic solvents for correlating with enzyme efficiency. It does not work well over the entire range of polarity but no better parameter has emerged so far [5]. One recent publication which provides a somewhat different perspective and deserves more attention than it has got is by Paez et al., (2003) [6]. In the context of modelling the effect of free water on enzyme activity in immobilized lipase catalyzed reactions, authors believe that increasing amount of water entering the carrier pores reduces the number of enzyme molecules at the water solvent interphase and thereby hinders the accessibility of the hydrophobic substrates. The enzyme in low water still 
requires same ionization states of the amino acid side chains (especially of active site residues) as present when enzyme is at the $\mathrm{pH}$ optimum in aqueous buffers. Hence, use of solid state buffers and drying enzymes from aqueous buffers at $\mathrm{pH}$ optimum is desirable [7]. From phenomenological point of view, it indicates that the mechanism of the reaction does not change in low water media. Only the direction of the reaction changes when hydrolases are used since water for hydrolysis is not adequately available. In fact, hydrolysis and synthetic modes compete with each other. Hence, the need for optimization of water level arises. This also means that if optimum $\mathrm{a}_{\mathrm{w}}$ is lowered by biocatalyst engineering, it improves conversions in the direction of synthesis.

The confusion between stability and catalytic efficiency Even in the literature on enzyme catalysis in the conventional media of aqueous buffers, sometimes there has been lack of clarity about the concept of enzyme stability. There is storage stability which refers to how long an enzyme preparation can be stored under particular conditions. Stability towards a "stress" (denaturing and/or harsh) conditions is measured by an exposure of the enzyme preparation to that particular condition for a specific period of time and finding out decrease (if any) in the enzyme activity by reverting to normal conditions and/or conditions under which enzyme is generally assayed. This change is a measure of irreversible inactivation. Measuring enzyme activity under the reactor conditions is operational stability. While reporting change in enzyme activity (over a control) in organic solvents any higher initial rates or \% conversion is quite often referred to as having stabilized the enzyme. May be so or may be that a particular formulation or a particular step (such as immobilization) has simply resulted in greater catalytic efficiency. After all the initial excitement, the reality check is in place that enzymes in low water media almost never reach $\mathrm{k}_{\mathrm{cat}} / \mathrm{K}_{\mathrm{m}}$ values which are reported for the same enzyme in aqueous buffers [1].

\section{Various attempts at improving catalytic efficiency}

Broadly, such attempts can be classified as follows:

i. PEG-modified enzymes soluble in some organic solvents $[8,9]$.

ii. Enzymes entrapped within a gel [10].

iii. Immobilized enzymes [11].

iv. Enzyme-Polymer complexes [12].

(a) Chemical modification [13].

(b) Surfactant/Lipid coated enzyme [14-17].

v. Enzymes lyophilized with cryoprotectants \pm lyoprotectants [18], salts at high concentrations (exemplified notably by $\mathrm{KCl}$ [19-22], other additives like crown ethers and cyclodextrins etc [1]).

vi. Enzymes "dried" by precipitation with organic solvents [23-25].

vii. Enzymes crystallized and crosslinked [26-28]/enzymes crosslinked extensively after precipitation.
While the primary focus of this review is on (vi) \& (vii), few comments and examples on other approaches may be in order. One of the most impressive results has been reported by lyophilizing enzymes in presence of high concentration of $\mathrm{KCl}$. Given the impressive result, one would have expected lot of people switching over to this formulation. Yet only few laboratories seem to use it. We need wider experience with these formulations. An excellent review on this approach has been recently published [29]. The major problem in evaluating any improvement in catalytic efficiency has been two fold: (a) Reliable assay measurements. To get some idea about the seriousness of this issue, the reader is referred to [30] for a discussion on this with lipase as a focus. (b) What is being compared with what? Numerous papers report a method of immobilization and an initial rate/\% conversion obtained with the immobilized preparation in the case of an arbitrarily chosen reaction in an arbitrarily chosen set of media. Hence, it is seldom possible to assess any improvement which a particular method has achieved over existing ones.

\section{Enzyme precipitated and rinsed with organic solvents (EPROS)}

Partridge et al., (1998) [20] described a simple high activity preparation for Subtilisin Carlsberg (SC) and a-chymotrypsin by precipitating them by $n$-propanol over silica gel. The preparation was "dried" by rinsing with $n$-propanol and called propanol rinsed enzyme preparations (PREP).

Roy and Gupta (2004) [31] showed that a similar high activity preparation could be obtained even as a free enzyme. a-Chymotrypsin was precipitated from a buffered solution of appropriate molarity by $n$-propanol and repeatedly rinsed with the same organic solvent gave a "dry" precipitate from which all excess water had been removed. The preparation called EPRP gave 132 times higher initial rates for esterification in $n$-octane. This was in comparison with lyophilized powders. No $a_{w}$ control was maintained during the measurements of initial rates so it is likely that these initial rates were underestimated. Shah and Gupta (2007) [32] subsequently showed that an EPRP of SC gave about 10,000 times increase in initial rates for transesterification in the ionic liquid [Bmim] $\left[\mathrm{PF}_{6}\right]$ as compared to so called $\mathrm{pH}$ tuned lyophilized powders. The EPRP showed limited activity even in water soluble ionic liquid $[\mathrm{Bmim}]\left[\mathrm{BF}_{4}\right]$ wherein $\mathrm{pH}$ tuned lyophilized $\mathrm{SC}$ showed no activity whatsoever. EPRP of Candida rugosa lipase (CRL) was evaluated for kinetic resolution of ( \pm )-1-phenylethanol in [Bmim] $\left.\mathrm{PF}_{6}\right]$. EPRP gave an E value of 153 [2]. In the same work it was reported that acetone was a better solvent for precipitation and rinsing in case of Burkholderia cepacia lipase (BCL). Hence a more general name for the preparation, Enzyme Precipitated and Rinsed with Organic Solvent (EPROS) was given. EPROS of $B C L$ gave $E>1000$ in just 2 hours for the above kinetic resolution. The untreated enzyme powders performed poorly. Solanki and Gupta (2008) [33] showed the conceptual linkage between EPRP and PCMC (Protein Coated 


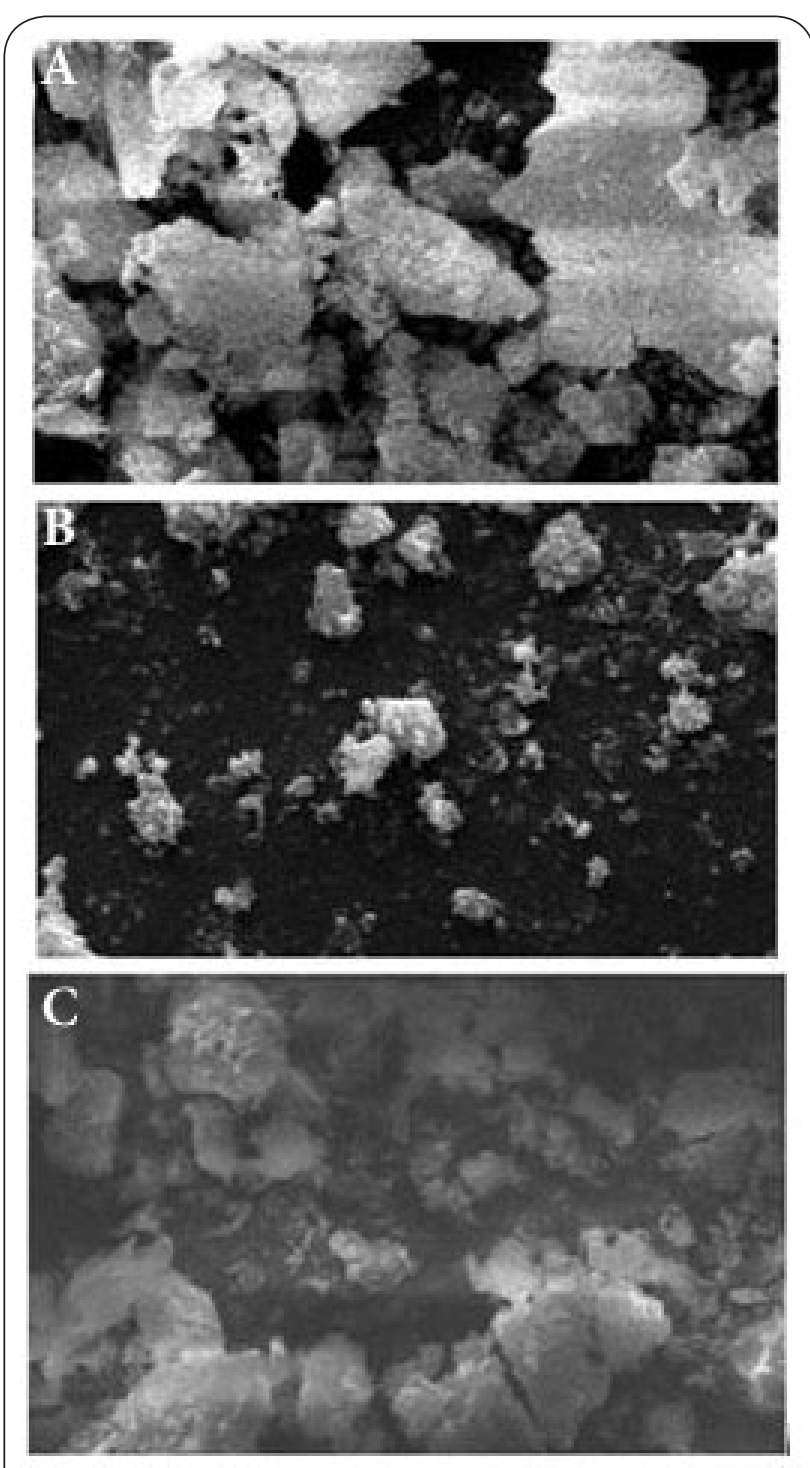

Figure 1. Scanning electron microscopy (SEM) images (A) EPRP of $\alpha$-chymotrypsin ( 0 percent trehalose) precipitated into n-propanol (magnification: $5000 \times$ ). (B) EPRP of a-chymotrypsin (5 percent trehalose) precipitated into $n$-propanol(magnification: $5000 \times$ ). (C) PCMC of $\alpha$-chymotrypsin (40 percent trehalose) precipitated into n-propanol (magnification: 5000×). SEM was carried out on a Zeiss EVO50 scanning electron microscope. Samples were dried by rinsing with anhydrous propanol, placed on a sample holder, and coated with silver before being scanned in vacuo. [reproduced from Solanki and Gupta, 2008 with permission from publishers].

Micro Crystals; see later for a discussion on PCMC) designs. EPRP of a-chymotrypsin was prepared in presence of trehalose. As trehalose amount increased, EPRP morphed into PCMCs (Figure 1). PCMCs, in this case were found to give much higher rates as compared to EPRP. The biocatalyst preparations were evaluated both in $n$-octane and acetonitrile.

There has been much concern about low activity or absence of activity of lipases towards $t$-alcohols and their derivatives as substrates. Majumder and Gupta (2011) [34] showed that when EPROS of CRL were prepared by precipitation and rinsing with $t$-alcohols like $t$-butyl alcohol or $t$-amyl alcohols, then catalytic activity for transesterification of tributyrin with $t$-alcohols increased about 41 times as compared to lyophilized powders. Again, not many groups seem to have used EPRP and PREP. We need wider trials for these simple approaches.

\section{Crosslinked enzyme crystals (CLEC)}

Clair and Navia (1992) [26] described CLEC design exemplified by thermolysin. These were prepared by crosslinking of microcrystals of $\sim 10^{-1} \mathrm{~mm}$ size by glutaraldehyde. It was shown that $C L E C$, unlike the powders of free enzyme, retained almost complete activity upon exposure to acetonitrile, dioxane, acetone and THF for 1 hour. A careful look at the experimental protocol would show that the medium was actually aqueous-organic cosolvent mixture. Partridge et al., (1996) [35] used CLEC of Subtilisin in anhydrous acetonitrile for a transesterification reaction. They observed that the best way of "drying" CLECs was by rinsing with dry organic solvents. Khalaf et al., (1996) [36] used CLECs of CRL and/ or $\mathrm{BCL}$ for resolution of the alcohols, acids and amines in the dry organic solvents. These workers used solutions of surfactants in organic solvents for drying CLECs. CRL-CLEC showed higher enantioselectivity as compared to free and crude CRL which authors believed could be due to "removal of competing hydrolases".

Wang et al., (1996) [37] from the same group reported that the high enantioselectivity of CLEC of subtilisin towards the substrate (L)-amino acids and (S)-amines resulted in the production of $(\mathrm{S}, \mathrm{S})$-alkyl amides even when starting molecules are not optically pure. The enzyme formulation worked with a broad range of substrates; acetonitrile was found to be the best solvent among several tried. It is noteworthy that no reaction occurred when DMF was used as solvent. No loss in catalytic performance was reported even after 7 cycles of use. Lalonde et al., (1997) [28] described use of CLECs of lipases in kinetic resolution of acids and alcohols. Typical of articles in volumes of this invaluable series, this provides a good introduction to the biocatalyst design and offers many helpful practical suggestions. The article included several applications which involved use of nearly anhydrous organic solvents for enantiospecific esterification. Higher initial rates and enantioselectivity were reported with CLECs as compared to the corresponding free enzyme. Pepin and Lortie (2001) [38] used CLEC prepared from CAL $B$ for esterification of $(R, S)$ Ibuprofen with dodecanol in octane and found that just like Novozyme-435 (an immobilized form of Candida antarctica lipase B (CAL B) sold by Novozymes, Denmark), CLEC also gave best performance at $a_{w}=0.1$. An interesting comparison with CLEC design has shown [27] that colyophilization of Subtilisin 
Gupta et al. Universal Organic Chemistry 2013,

Carlsberg with methyl-cyclodextrin results in an enzyme preparation which provides better rates and enantioselectivity in organic solvents. CLECs, while a highly efficient design, requires a pure enzyme to start with. Given the high cost of protein purification, this becomes a serious disadvantage.

\section{Crosslinked enzyme aggregates (CLEA)}

In recent years, Sheldon and his coworkers [23] described preparation of CLEAs wherein enzyme precipitates, "the preorganized superstructure of the aggregates" were crosslinked to insoluble aggregates. A major advantage of CLEAs over crosslinked enzyme crystals (CLECs) is that unlike the latter, CLEAs do not necessarily require pure enzyme. Earlier, a large number of insoluble enzyme aggregates had been described in the literature [39-41]. These were prepared by extensive cross linking of enzyme solutions. These insoluble aggregates were lot more amorphous in morphology [41]. Glutaraldehyde is undoubtedly the most frequently used crosslinking reagent in science and has also been the one generally used for preparing CLEAs $[42,43]$. It has been shown that varying extent of crosslinking of $\mathrm{BCL}$ (by simply employing different concentration of glutaraldehyde) can give CLEAs which give different initial rates and enantioselectivity in low water media [24]. The preparation of CLEAs with different variations of the basic methodology has been described at a number of places $[42,43]$. While precipitation with organic solvents has been most often used, salts and polymers have also been used. Co-precipitation of the enzyme with polyethyleneimine (PEI) or PEI-dextran sulphate mixtures has been reported to produce significant changes in activity, specificity and enantioselectivity of the enzyme due to introduction of different microenvironments around the enzyme active site $[42,43]$. Similarly, presence of additives such as surfactants, crown ethers and amines during formation of CLEAs of lipases "locked" the enzymes in the more active conformation. Up to ten times the activity of the free enzyme in organic solvents could be obtained [44]. The low protein content in starting commercial preparation in case of Amano ${ }^{\circledR}$ lipase from Pseudomonas cepacia led to poor crosslinking. Addition of Bovine Serum Albumin (BSA) as a "proteic feeder" not only solved that problem but led to higher operational stability in organic solvents [45].

After the above general picture, it is useful to look at the specific results obtained with this biocatalyst design in low water media. The use of CLEAs of Penicillin G Acylase [46] led to the synthesis of ampicillin in a broad range of solvents. Interestingly, neither the reaction rate nor ratio of synthetic to hydrolytic activities ( $\mathrm{S} / \mathrm{H}$ ratio) correlated well with $\log \mathrm{P}$, the highest ratio being observed in acetonitrile. Authors also claimed that the CLEA design was more efficient than even CLEC design by $50 \%$ for this synthesis in terms of initial rates. A subsequent study reported that CLEAs showed a comparable $\%$ conversion to free enzyme ( $85 \%$ vs. $88 \%$ respectively), the corresponding $\mathrm{S} / \mathrm{H}$ ratio at those \% conversions was 1.58 and 2.0 respectively [47]. Surprisingly, the \% conversion reported in various organic solvents correlated well with log P. Acetonitrile was again reported to show highest $\mathrm{S} / \mathrm{H}$ ratio. Langen et al., (2005) [48] reported preparation of cyanohydrins for several aldehydes using a CLEAs of (R)-oxynitrilase under microaqueous conditions. The 10 times recycling of the biocatalyst was possible without loss of activity. Excellent conversions up to $99 \%$ with good enantioselectivity were observed in several cases. Employing low water conditions suppressed the non-enzymatic reactions and hence improved enantioselectivity.

The CLEA particles have a size range of 0.5-200 $\mu$ with an average of $12 \mu$ [42]. It was estimated that "a single CLEA particle contains a maximum of $8 \times 106$ enzyme molecules" with CAL B as an example [42]. It was pointed out "CLEAs can form large clusters which do have mass transport limitations". The clusters can be as large as $100 \mu \mathrm{m}$ and CLEAs in a cluster can vary widely "from a few hundred to a few thousand". Cluster size was found to have effect on activities if fast assays were used. CAL B formed very large and hydrophobic clusters which showed higher activity with fast spectrophotometric assay as compared to the slower titration based assay. While both assays tracked hydrolysis of the ester bond, mass transfer limitations could be seen in the titration based assay. On the other hand, glycosylated enzymes ss-Galactosidase formed "well dispersible suspensions" which showed no difference in activities when assayed by two different fast and slow assays [42]. The issue of cluster size and nature of enzyme molecule had been studied at a greater length by the same group [49]. Majumder et al., (2008) [24] showed that extent of crosslinking also affected cluster size and same enzyme can give CLEA clusters of different morphology and size.

Novozyme 435 is an immobilized preparation of CAL B sold by Novozymes, Denmark. It is one of the most frequently used enzyme preparation in organic biotransformation. The reason is that it often shows very good catalytic performance in the case of numerous reactions carried out in low water media. Sheldon (2006) [23] claims that CLEA prepared from CAL B by a patented procedure for organic media surpasses even Novozyme 435 in catalytic performance in low water organic solvents, ionic liquids and supercritical $\mathrm{CO}_{2}$.

Alternative protocols for preparing CLEAs continue to be developed. Sometime back, it was mentioned that reducing the size of CLEAs by using a reciprocating mixing device increased the catalytic activity of CLEAs of $\mathrm{N}$-acetyl-D-neuraminic acid aldolase for catalyzing condensation of pyruvate and $\mathrm{N}$-acetylD-mannosamine. While this particular application was carried out in aqueous buffers, it may be interesting to test this in low water media, wherein, mass transfer constraints play an even bigger role. Arsenault et al., (2011) [50] used chitosan as a poly functional molecule to crosslink free accessible carboxyl groups in laccase using the well known carbodiimide chemistry. One of the known applications of laccase is in dye removal from waste water. The CLEAs of laccase were found to show higher 
stability towards a chosen waste water sample. However, the stability towards chemical denaturants as compared to the free enzyme did not improve.

Winter et al., (2012) [51] imprinted sucrose phosphorylase with a-glucosyl glycerol before cross linking to improve the specific activity with glycerol (as an acceptor of a-glucosyl residues). Again these "iCLEA" were used in aqueous media for reversible phosphorylysis of sucrose.

Talekar et al., (2012) [52] mixed amino-functionalized $\mathrm{Fe}_{3} \mathrm{O}_{4}$ nanoparticles with alpha-amylase before initiating precipitation and crosslinking with glutaraldehyde. The intent was to prepare CLEAs which can be separated by magnetism. Also, it was argued that high amino group density on nanoparticle surfaces will substitute for a proteic feeder as alpha-amylase used had only few lysine residues. An interesting variation of the CLEA concept has been described by Gan et al., (2012) [53]. The adsorbtion of glucoamylase on thermosensitive crosslinked gelatin nanoparticles was carried out. The enzyme was released by swelling of the gelatin nanoparticles in the temperature range of $40-80^{\circ} \mathrm{C}$ which coincides with the appropriate temperature range at which amylase is used for starch hydrolysis. The swelling-shrinking of crosslinked gelatin nanoparticles was reversible; unfortunately the release of the enzyme was not. Hence, the design has little practical application. It may be interesting to recall the seminal work of Hoffman's group with beta-galactosidase immobilized on a smart poly-NIPAAm thermosensitive hydrogel [54]. That work is not quoted by Gan et al., perhaps because it did not involve any crosslinking while making the smart hydrogels nor the size of the poly-NIPAAm gels were in the nano range. In that system, the enzyme was not released. However, the thermal cycle converted the immobilized enzyme into a 'pump' who threw out the product; thus relieving the product inhibition!

CLEAs, just like CLEC, do not involve any support for immobilization, hence CLEAs and CLEC represent examples of carrier-free immobilization leading to high volumetric activities.

\section{Protein coated microcrystals (PCMC)}

Kreiner et al., (2001) [55] reported a "method for high activity biocatalyst preparation" called enzyme coated microcrystals or protein coated microcrystals. In view of latter, the acronym PCMC is generally used for such preparations. In the preparation protocol, an aqueous solution of a protein is mixed with a concentrated solution of an excipient such as salt (eg., $\mathrm{K}_{2} \mathrm{SO}_{4}$ ), a sugar or an amino acid is added dropwise with mixing to a water miscible organic solvent like propanol. Micron sized crystals of the excipient with the enzyme (about $8 \% \mathrm{w} / \mathrm{w}$ ) coated on the surface are obtained. In the case of Subtilisin Carlsberg (SC), PCMCs gave100 times higher initial rate than " $\mathrm{pH}$ tuned" freeze dried preparation [55]. The recommended best way of storing PCMCs was in the precipitating solvent itself. Many commercial lipases with PCMC formulation also showed enhanced initial rate as well as $\%$ conversion during kinetic resolution of $(\mathrm{R}, \mathrm{S})$-phenylethanol by converting it to (R)-phenyl ethyl acetate with vinyl acetate as donor. No change in enantioselectivity was observed though the lipases (as received from the vendor) tried already showed E>200. Farrell et al., (2006) [56] reported that (a) PCMCs show no diffusion control (b) PCMC of SC when evaluated by active site titration with PMSF (using a newly developed ESI-MS based method) showed much greater accessibility than the corresponding lyophilized sample of the enzyme; $43 \%$ vs. $14 \%$ respectively at $\mathrm{a}_{\mathrm{w}} \sim 0$. At $\mathrm{a}_{\mathrm{w}}=0.5\left(\sim 10 \% \mathrm{v} / \mathrm{v} \mathrm{H}_{2} \mathrm{O}\right.$ in ethanol), PCMCs of SC showed 98\% inhibition with PMSF (against $62 \%$ for the lyophilized sample). This shows that integrity of the active site is not preserved during lyophilization of enzymes.

Kreiner et al., (2005) [57] extended the study of the performance of PCMC formulation in organic solvent to oxidoreductases: Horse liver alcohol dehydrogenases (HLADH), catalases and peroxidases from both soybean and horseradish. While PCMCs in general showed enhanced reaction rates, the highest increase of 50 times was reported for HLADH. In case of HLADH, the coenzyme also precipitates along with PCMC formation. The storage and operational stabilities of PCMCs of CAL B and SC have also been described [57]. Transesterification activity assay was used in this work for evaluating all stabilities. As mentioned for PCMC of SC, PCMCs of CAL B also showed high storage stability when stored in propanol (containing $1 \% \mathrm{w} / \mathrm{w} \mathrm{H}_{2} \mathrm{O}$ ). Both PCMCs could be stored at room temperature and even after 1 year only $10 \%$ loss in activity was observed. When propanol $\left(1 \% \mathrm{w} / \mathrm{w} \mathrm{H}_{2} \mathrm{O}\right)$ was used as a reaction medium, SC-PCMC could be reused four times with only $16 \%$ loss in activity. On the other hand, these PCMCs lost activity rapidly ( $>50 \%$ ) within 4 hours in a continuous flow reaction if THF and acetonitrile (both with $1 \% \mathrm{w} / \mathrm{w}$ water) were used as the reaction medium. Shah et al., (2007) [58] examined the PCMC of BCL by atomic force microscopy (AFM) which confirmed the enzyme coating over $\mathrm{K}_{2} \mathrm{SO}_{4}$ microcrystals. The PCMC gave $96 \%$ conversion of jatropha oil to biodiesel in $90 \mathrm{~min}$, whereas free enzyme gave only $8 \%$ conversion under similar conditions.

Earlier [59], it was shown that use of solid state buffers instead of $\mathrm{K}_{2} \mathrm{SO}_{4}$ as the core for preparing PCMCs of SC and chymotrypsin resulted in 3-fold increase of activity in acetonitrile. On the other hand, this result was not observed with lipases. Authors believe that this may be due to lower acid sensitivity of lipases. Shah and Gupta (2007) [2] investigated the use of PCMCs of CRL and BCL for kinetic resolution of $( \pm)$ phenylethanol in the ionic liquid $\left[\mathrm{Bmim}^{-}\left[\mathrm{PF}_{6}\right]\right.$ by transesterification with vinylacetate. The performances of PCMCs were also compared with EPROS, PREP and CLEA formulations (Table 1). PCMC of CRL was best and at $25^{\circ} \mathrm{C}$ gave an E-value of 453 (with $44 \%$ conversion in 12 hours). For BCL, EPROS, CLEA and PCMC all worked well with $50 \%$ conversion and $99 \%$ ee $_{p}(E>1000)$ in just 2 hours. To put this result in proper perspective, free $\mathrm{BCL}$ gave only $8 \%$ conversion under the same conditions. 
Gupta et al. Universal Organic Chemistry 2013,

http://www.hoajonline.com/journals/pdf/2053-7670-1-1.pdf

doi: $10.7243 / 2053-7670-1-1$

Table 1. Kinetic resolution of 1-phenylethanol in [Bmim] $\left[\mathrm{PF}_{6}\right]$ catalyzed by different preparations of $\mathrm{BCL}$ at $25^{\circ} \mathrm{C}$ [Reproduced from Shah and Gupta, 2007 [2] with permission from publishers].

\begin{tabular}{clccccc}
\hline Entry & $\begin{array}{l}\text { Lipase } \\
\text { Preparations }\end{array}$ & Time (h) & $\begin{array}{c}{ }^{\mathrm{a}} \text { Conversion } \\
(\mathbf{\%})\end{array}$ & $\mathbf{a}_{\mathbf{p}}$ & ${ }^{\mathrm{a}_{\mathbf{s}}} \mathrm{e}_{\mathrm{s}}$ & ${ }^{\mathrm{b}} \mathbf{E}$ \\
\hline 1 & pH Tuned & 1 & 5 & 99 & 5 & 114 \\
2 & pH Tuned & 2 & 8 & 99 & 8 & 187 \\
3 & EPRA & 1 & 31 & 99 & 45 & 314 \\
4 & EPRA & 2 & 49 & 99 & 96 & 736 \\
5 & AREP & 1 & 44 & 99 & 78 & 415 \\
6 & AREP & 2 & 50 & 99 & 99 & $>1000$ \\
7 & CLEA & 1 & 41 & 99 & 69 & 432 \\
8 & CLEA & 2 & 50 & 99 & 99 & $>1000$ \\
9 & PCMC & 1 & 40 & 99 & 66 & 405 \\
10 & PCMC & 2 & 50 & 99 & 99 & $>1000$ \\
\hline
\end{tabular}

${ }^{\mathrm{a}}$ Conversion and ee's (\%) were estimated by HPLC.

${ }^{b} \mathrm{E}=\ln [1-\mathrm{c}(1+$ eep $)] / \ln [1-\mathrm{c}(1-$ ees $)]$, where $\mathrm{c}=$ ees/(ees +eep).

Crosslinked protein coated microcrystals (CLPCMC) Shah et al., (2008) [60] described preparation of CLPCMCs of SC, CRL and BCL by crosslinking of corresponding PCMCs with glutaraldehyde. The CLPCMCs were found to show higher reaction rates than PCMCs for transesterification in different organic solvents which included polar solvents like acetonitrile and THF. The highest increase (133\%) in initial rates for SC over the corresponding PCMC was observed in $t$-amyl alcohol. For $C R L$ and $B C L$, the highest increase in initial rates were seen in octane $(445 \%)$ and THF $(180 \%)$ respectively. In the case of transesterification reaction catalyzed by SC formulations at $70^{\circ} \mathrm{C}$, while $\mathrm{PCMC}$ required $0.5 \%(\mathrm{v} / \mathrm{w})$ water for optimum conversion, CLPCMC required no addition of water for comparable conversion in the same time period. The obvious advantage of being able to work with much lower water content was that no hydrolysis product was formed with the CLPCMC [60]. CLPCMC design is beginning to be tested in different laboratories. Yan et al., (2011) [61] used CLPCMC of lipase from Geotrichium species for catalysing biodiesel from waste cooking oil. It is very unfortunate that Yan et al., (2011) [61] referred to the earlier paper of Shah et al., (2008) [60] as merely PCMC and implied that they were describing a novel biocatalyst design. Recently, Solanki and Gupta (2011) [62] have further refined the CLPCMC design and showed that CLPCMC prepared from BCL after modification with pyromellitic dianhydride (PMDA) worked well even in DMF. In a first report of an enzyme formulation which works reasonably well even in DMF, it was shown that an initial rate of $7.2 \mathrm{nmol} \mathrm{min}{ }^{-1} \mathrm{mg}^{-1}$ could be observed at $5 \%(\mathrm{v} / \mathrm{v})$ water content for transesterification of tributyrin with hexanol. The unmodified $\mathrm{pH}$ tuned lipase showed no activity at all in DMF.

\section{Three phase partitioning (TPP) of enzymes}

TPP is a bioseparation strategy which consists of mixing in a salt (generally ammonium sulphate is used) and an organic solvent ( $t$-butanol has been most frequently used) in appropriate amount to an aqueous solution of a protein. In less than one hour or so, under gravity or gentle centrifugation, three layers separate out. The protein/enzyme form an interfacial precipitate between upper $t$-butanol rich layer and lower water rich layer [63]. Hence while its name has the word "partitioning" because of the early conceptual development and applications, it is essentially a precipitation technique.

Roy et al., (2004) [64] showed that subtilisin subjected to three phase partitioning gave higher initial rates for transesterification in octane and $t$-amyl alcohol. When the precipitate was dried by lyophilization in the presence of a cryoprotectant and a lyoprotectant $[1,64,65]$, the overall increase in initial rates (as compared to untreated enzymes) was $\sim 1200$-1800 times. Presumably, enhanced conformational flexibility was atleast a contributing factor to this enhanced catalytic efficiency. It is well established that enzyme conformation tends to be more rigid in such solvents [66]. The catalysis requires numerous conformational changes at various steps and higher rigidity or stability often comes out at the cost of catalytic efficiency. Earlier X-ray diffraction results with TPP treated Proteinase K had shown that the enzyme was considerably more flexible after this treatment [67].

Subsequently, Shah and Gupta (2007) [32] showed that TPP-treated SC also showed 10,000 times increase in initial rates (over lyophilized powders of untreated enzyme) in the ionic liquid $[\mathrm{Bmim}]\left[\mathrm{PF}_{6}\right]$. Obviously this simple approach has been underexploited and it is possible that we will see more interesting result with this simple treatment. Perhaps, one needs to gain greater understanding about structural consequences of TPP treatment of enzymes. Recent results show that TPP treatment does not always result in increase in conformational flexibility [68].

Rather et al., (2012) [68] studied the structural consequences of TPP treatment using alpha chymotrypsin as a model enzyme. It was found that alpha-chymotrypsin subjected to TPP formed soluble aggregates. Nevertheless, these aggregates had higher activity in both aqueous and non-aqueous conditions.

\section{Catalytic promiscuity in nearly anhydrous organic solvents}

Hult and Berglund (2007) [69] classified enzyme promiscuity into three classes: condition promiscuity, substrate promiscuity and catalytic promiscuity. Enzymes carrying out different catalytic activities (from those in aqueous buffers) in nearly anhydrous organic solvents can be said to exhibit condition promiscuity (Figure 2). In that sense whole of this review pertains to enhancement of condition promiscuity of enzymes in such media! The substrate promiscuity refers to the fairly well known phenomenon of broad substrate specificity of enzymes. It is catalytic promiscuity which is a relatively more recently discovered phenomenon wherein enzymes catalyze chemical reactions other than the ones which they normally are known to catalyze. These chemical reactions are distinct enough to involve different transition states. While 


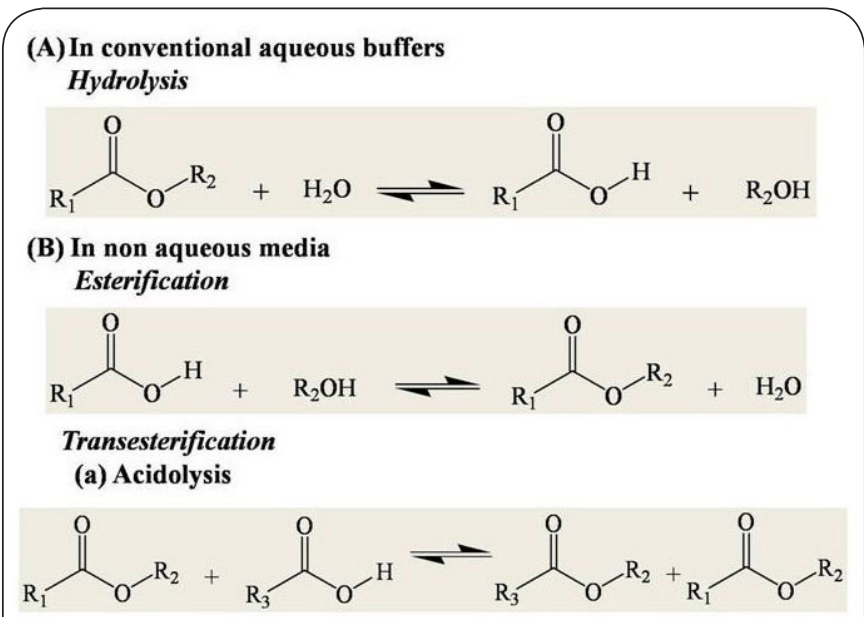

(b) Aminolysis

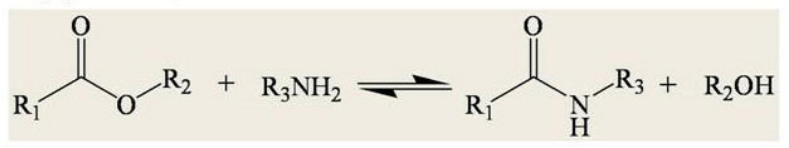

(c) Alcoholysis

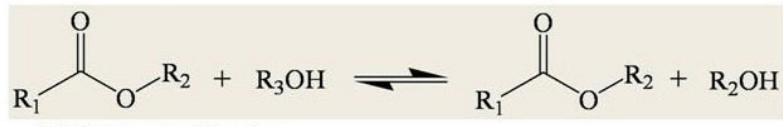

(d) Interesterification

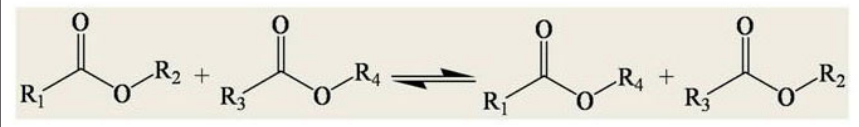

Figure 2. Condition Promiscuity shown by Lipases (A) in conventional aqueous buffers (B) in low water media.

considerable amount of work has been already reported on "induced catalytic promiscuity" which involves enzymes engineered by protein engineering and directed evolution methods $[69,70]$ we will again restrict ourselves to "accidental catalytic promiscuity" shown by wild enzymes in low water containing organic solvents. As Busto et al., (2010) [70] have recently reviewed this as well extensively, only brief treatment will be provided here with a focus on the current status of catalytic efficiency in such cases. Hydrolases, especially lipases, have been the focus of attention in many studies which report catalysis of C-C bond or C-heteroatom bond. Larger percentage of these studies has involved aqueous-organic co-solvent mixtures as reaction medium rather than nearly anhydrous organic solvents [70]. However, some interesting results in low water containing organic solvents as reaction medium have also been reported.

Li et al., (2008) [71] reported that porcine pancreatic lipase catalysed aldol condensation between substituted aromatic aldehyde with acetone in a solvent free system. While the reaction could be observed under nearly anhydrous conditions with fairly good enantioselectivity ( $e e=43.6 \%$ ) optimum water concentration was $20 \%(\mathrm{v} / \mathrm{v})$ for obtaining nearly $50 \%$ yield in 75 hours. Presumably, enantioselectivity was much lower at higher percentage conversions. Majumder et al., (2009) [72] showed that Novozyme-435 could catalyze a condensation reaction between a cylic diketone with acetaldehyde. The latter was produced from vinyl acetate in situ enzymatically under low water conditions. The reaction medium was "solvent free" but with $10 \%$ DMF or pyridine as the "co-solvent". The reaction required just 4 hours for $100 \%$ conversion.

Cai et al., (2004) [73] described Michael addition of imidazole with acrylates by an alkaline protease from Bacillus subtilis. The yield varied from $62-76 \%$ with pyridine as the solvent at $50^{\circ} \mathrm{C}$ in 72 hours. Such products are useful in the treatment of protozoal infections. A more extensive study of this reaction was also reported later [74]. Liu et al., (2008) [75] screened several commercially available lipase preparations for carrying out aza-Markonikov addition of $\mathrm{N}$-heterocycles to vinyl esters in organic solvents. Lipase from Mucor javanicus worked best while several other frequently used lipases Candida antarctica lipase B, Candida rugosa lipase and Mucor miehei lipase showed very poor activity. The addition took place at $\mathrm{C}=\mathrm{C}$ and not $\mathrm{C}=\mathrm{O}$ group of vinyl acetate. DMSO and DMF (to a lesser extent) were the best reaction media whereas in non polar solvents like hexane poor activity was observed which presumably was largely due to poor solubility of substrates. The work also reports combination of catalytic promiscuity (aza-Markonikov addition) with a normal reaction (transesterification) to produce octane-1, 2-propanediol derivatives of $\mathrm{N}$-heterocycles. These are important drug derivatives.

Priego et al., (2009) [76] described use of medium engineering to control the chemoselectivity between a Michael addition and the aminolysis product when benzyl amine and methyl crotonoate were reacted in the presence of CAL B. Whereas hydrophobic solvents favoured Michael addition, aminolysis occurred in more polar solvents.

Earlier, Qian et al., (2007) [77] reported that bacterial acylases could also catalyze aza-Michael addition of aromatic $\mathrm{N}$-heterocycles to $a, \beta$-unsaturated compounds in DMSO and DMF. Reasonable yields $>80 \%$ were obtained in several cases with reaction times in the range of 0.5-6 hours. In general, reaction times tend to be long in most of the promiscuous reactions: $s 0 \leq 10$ hours reaction times reported (for maximum and high conversions) in this work [77] and by Majumder et al., (2009) [72] are noteworthy. Wu et al., (2005) [78] had also used an acylase- Penicillin G acylase for catalyzing Markonikov's addition of allopurinol to vinyl ester. An interesting observation is that even for a promiscuous reaction, an immobilized enzyme gave higher initial rate than the free enzyme in DMSO. The conversion to give an optically active product was $\sim 60 \%$ in 144 hours with vinyl acetate. Earlier, Torre et al., (2004) [79] reported Michael addition of secondary amines to acrylonitrile in a solvent free system using different preparations of CAL B. Both Wu et al., (2005) [78] and Torre et al., (2004) [79] discussed the possible mechanism for the 
Gupta et al. Universal Organic Chemistry 2013,

enzyme catalyzed reaction which does involve active site of the enzymes. Lou et al., (2008) [80] showed that selectivity between Markonikov addition and anti-Markonikov addition of thiols to vinyl esters catalyzed by CAL B can be altered by changing the reaction medium. More polar solvents DMF favored anti-Markonikov addition whereas di-isopropyl ether favored Markonikov addition. The work, incidentally, outlines a synthetic route to C-S bond formation using lipases in low water containing organic solvents. Carboni-Oerlemans et al., (2006) [81] reviewed synthesis and use of peroxycarboxylic acids in anhydrous media using hydrolases in general. Several interesting results have been highlighted. Yadav and Devi (2002) [82] showed the synthesis of a peracid using CAL B in toluene. The peracid formed in situ has also been shown (a) to carry out Prileshajev oxidation of double bonds (b) S-oxidation of Penicillin G (c) Baeyer Villiger oxidation.

It is thus important to note that even with commercially available enzymes; many examples of promiscuity of enzymes other than lipases are available. At present, the amount of enzyme used is very high. Hence, these results are included more to show that such systems constitute a very meaningful target for investigating use of high activity preparations of enzymes.

\section{Nanobiocatalysts}

Large surface area to volume ratio makes nanosized materials as very attractive carriers for enzyme immobilization. As a comprehensive review has been recently published [83] on this topic, only few illustrative examples along with some updates will be given here.

To start with, Vertegel et al., (2004) [84] showed that size of the silica nanoparticle influenced the structure and activity of lysozyme. While this work had nothing to do with enzyme catalysis in low water media, it is worth mentioning as this is of fundamental importance and such data is not always available with various systems. Immobilization of Candida rugosa lipase (CRL) on multi walled carbon nanotubes (MWNTs) by adsorption led to 2.2 and 14 fold increase in transesterification activity in $n$-hexane and $\left[\mathrm{Bmim}^{-}\left[\mathrm{PF}_{6}\right]\right.$ respectively [85]. The immobilized lipase also showed high enantioselectivity in kinetic resolution of $( \pm)$-1-phenylethanol in $[\mathrm{Bmim}]\left[\mathrm{PF}_{6}\right]$. Similar work but using single walled carbon nanotubes (SWNTs) with several enzymes reported high activity in organic solvent than using conventional supports [86]. Both CRL and Burkholderia cepacia lipase (BCL) when adsorbed on zirconium nanoparticles modified by surfactants could be reused for 8 cycles [87]. The immobilized enzyme also showed higher enantioselectivity for the resolution of $(R, S)$-lbuprofen and $(R, S)$-phenylethanol in isooctane.

Recently, Solanki and Gupta (2011) [88] have described the simultaneous purification and immobilization of CRL on $\mathrm{Fe}_{3} \mathrm{O}_{4}$ nanoparticles after coating the latter with polyethylene imine (PEI). The immobilized lipase showed 110 times increase in initial rates of transesterification of ethyl butyrate with butanol in hexane over the commercial preparation. Use of a spinning cell accessory with circular dichroism (CD) instrument allowed recording CD spectra of the immobilized enzyme as well. No significant change in secondary structure upon immobilization could be detected. The immobilized enzyme could also resolve ( \pm )-1 phenylethanol (by transacetylation with vinylacetate) with $99 \% \mathrm{ee}_{\mathrm{p}}$ and $\mathrm{E}=412$. The commercial preparation did not show any significant conversion during the time period of 24 hours.

\section{Conclusion and future perspectives}

While there are numerous instances where enzymes have been employed in various industrial sectors $[\mathbf{8 9}, \mathbf{9 0}]$, however, their use in low water media for large scale organic synthesis is underexploited. There is an understandable diffidence on the part of organic chemists to switch over to these less familiar catalysts. None of the high activity preparations described here involve any skill or technology which is beyond an organic chemist or an organic chemistry laboratory.

Undoubtedly, given their huge role in development of greener chemical process, we will see larger applications of enzymes in low water media in the industry.

\section{Competing interests}

The authors declare that they have no competing interests.

\section{Authors' contributions}

\begin{tabular}{|l|c|c|c|}
\hline Authors' contributions & MNG & JM & DM \\
\hline Research concept and design & $\sqrt{ }$ & $\sqrt{ }$ & $\sqrt{ }$ \\
\hline Collection and/or assembly of data & $\sqrt{ }$ & $\sqrt{ }$ & $\sqrt{ }$ \\
\hline Data analysis and interpretation & $\sqrt{ }$ & $\sqrt{ }$ & $\sqrt{ }$ \\
\hline Writing the article & $\sqrt{ }$ & $\sqrt{ }$ & $\sqrt{ }$ \\
\hline Critical revision of the article & $\sqrt{ }$ & $\sqrt{ }$ & $\sqrt{ }$ \\
\hline Final approval of article & $\sqrt{ }$ & -- & -- \\
\hline Statistical analysis & -- & $\sqrt{ }$ & -- \\
\hline
\end{tabular}

\section{Acknowledgement}

Funds obtained from the Government of India's Department of Science and Technology (DST) [Grant No.:SR/SO/ BB-68/2010] and Department of Biotechnology (DBT) [Grant No.: BT/PR14103/BRB/10/808/2010] are gratefully acknowledged. JM thanks the Council of Scientific and Industrial Research for the Senior Research Fellowship.

\section{Publication history}

Editor: Rafael Luque, University of Cordoba, Spain.

EIC: Moinuddin Sarker, Natural State Research, Inc., Stamford, USA. Received: 27-Jul-2013 Revised: 13-Sep-2013

Accepted: 17-Sep-2013 Published: 27-Sep-2013

\section{References}

1. Lee MY and Dordick JS. Enzyme activation for nonaqueous media. Curr Opin Biotechnol. 2002; 13:376-84. | Article | PubMed

2. Shah $S$ and Gupta MN. Kinetic resolution of (+/-)-1-phenylethanol in [Bmim][PF6] using high activity preparations of lipases. Bioorg Med Chem Lett. 2007; 17:921-4. I Article I PubMed 
3. De Diego T, Manjon A, Lozano P and Iborra JL. A recyclable enzymatic biodiesel production process in ionic liquids. Bioresour Technol. 2011; 102:6336-9. | Article | PubMed

4. Bell G, Halling PJ, Moore BD, Partridge J and Rees DG. Biocatalyst behaviour in low water system. Trends Biotechnol. 1995; 13:468-473. | Article

5. Laane C, Boeren S, Vos K and Veeger C. Rules for optimization of biocatalysis in organic solvents. Biotechnol Bioeng. 1987; 30:81-7. | Article I PubMed

6. Paez BC, Medina AR, Rubio FC, Moreno PG and Grima EM. Modeling the effect of free water on enzyme activity in immobilized lipase catalyzed reactions in organic solvents. Enzyme Microb. Technol. 2003; 33:845853. | Article

7. Partridge J, Halling PJ and Moore BD. Solid state proton/sodium buffers: chemical pH stats for biocatalyst in organic solvent. J. Chem. Soc. Perkin Trans. 2000; 2:465-471. I Article

8. Ljungar $G$, Adlecreutz $P$ and Mattiasson B. Reactions catalyzed by PEG-modified a-chymotrypsin in organic solvents. Influence of water content and degree of modification. Biocatalysis. 1993; 7:279-288. | Article

9. Inada $Y$, Furukawa $M$, Sasaki $H$, Kodera $Y$, Hiroto $M$, Nishimura $H$ and Matsushima A. Biomedical and biotechnological applications of PEGand PM-modified proteins. Trends Biotechnol. 1995; 13:86-91. | Article I PubMed

10. Khmelnitsky YL, Neverova IN and Gedvovich AV. Catalysis by achymotrypsin entrapped into surface modified polymeric granules in organic solvent. Eur. J. Biochem. 1992; 210:751-757. | Pdf

11. Cao L (Ed.). Carrier-bound immobilized enzymes 2005.

12. Otamiri M, Adlercreutz P and Mattiasson B. Complex formation between chymotrypsin and ethylcellulose as a means to solubilise the enzyme in active form in toluene. Biocatalysis. 1992; 6:291-305. | Article

13. Basri M, Ampon K, Razak CAN and Salleh AB. Chemical Modification of Lipase for Use in Ester Synthesis. In Vulfson EN, Halling PJ, Holland HL (Eds.), Enzyme in non aqueous solvents: methods and protocols 2001; 65-76. | Book

14. Okahata $Y$ and Mori T. Lipid coated enzymes as efficient catalysis in organic media. Trends Biotechnol. 1997; 15:50-54. | Article

15. Mogi KI, Nakajima M and Mukataka S. Surfactant modification of lipases for lipid interesterification and hydrolysis reaction. J. Am. Oil Chem. Soc. 1999; 76:1259-1264. | Article

16. Sonesson AW, Elofsson UM, Brismar $\mathrm{H}$ and Callisen TH. Adsorption and mobility of a lipase at a hydrophobic surface in the presence of surfactants. Langmuir. 2006; 22:5810-7. | Article | PubMed

17. Adlercreutz P. Immobilisation and application of lipases in organic media. Chem Soc Rev. 2013; 42:6406-36. | Article | PubMed

18. Roy I and Gupta MN. Freeze-drying of proteins: some emerging concerns. Biotechnol Appl Biochem. 2004; 39:165-77. | Article | PubMed

19. Khmelnitsky YL, Welch SM, Clark DS and Dordick JS. Salts dramatically enhance the activity of enzymes suspended in organic solvents. J. Am. Chem. Soc. 1994; 116:2647-2648. | Article

20. Partridge J, Halling PJ and Moore BD: Practical route to high activity enzyme preparations for synthesis in organic media. Chem. Commun. 1998; 841-842. | Article

21. Solanki K, Gupta MN and Halling PJ. Examining structure-activity correlations of some high activity enzyme preparations for low water media. Bioresour Technol. 2012; 115:147-51. | Article | PubMed

22. Kuldamrong W, Husson F and Kermasha S. Biocatalysis with hydroperoxide lyase in extracts from Penicillium camemberti in neat organic solvent media. Biocatal. Biotransform. 2013; 31:94-99. | Article

23. Sheldon RA, Schoevaart R and Van Langen LM. Cross-linked enzyme aggregates. In Guisan JM (Ed.), Immobilization of enzymes and cells 2006, 31-45. | Book

24. Majumder AB, Mondal K, Singh TP and Gupta MN. Designing crosslinked lipase aggregates for optimum performance as biocatalysts. Biocatal. Biotransform. 2008; 26:235-242. | Article
25. Minteer SM. (Ed) Enzyme stabilization and immobilization: Methods and Protocols 2011. | Book

26. Clair NLS and Navia MA. Crosslinked enzyme crystals as robust biocatalyst. J. Am. Chem. Soc. 1992; 114:7314-7316. | Article

27. Montanez-Clemente I, Alvira E, Macias M, Ferrer A, Fonceca M, Rodriguez J, Gonzalez A and Barletta G. Enzyme activation in organic solvents: co-lyophilization of subtilisin Carlsberg with methyl-betacyclodextrin renders an enzyme catalyst more active than the crosslinked enzyme crystals. Biotechnol Bioeng. 2002; 78:53-9. | Article | PubMed

28. Lalonde JJ, Navia MA and Margolin AL. Cross-linked enzyme crystals of lipase as catalyst for kinetic resolution of acids and alcohols. Methods Enzymol. 1997; 286:443-464. | Article

29. Serdakowski AL and Dordick JS. Enzyme activation for organic solvents made easy. Trends in Biotechnol. 2007; 26:48-54. | Article | PubMed

30. Foresti ML and Ferreira ML. Frequent analytical/experimental problems in lipase-mediated synthesis in solvent-free systems and how to avoid them. Anal Bioanal Chem. 2005; 381:1408-25. | Article | PubMed

31. Roy I and Gupta MN. Preparation of highly active alpha-chymotrypsin for catalysis in organic media. Bioorg Med Chem Lett. 2004; 14:2191-3. I Article I PubMed

32. Shah $\mathrm{S}$ and Gupta MN. Obtaining high transesterification activity for subtilisin in ionic liquids. Biochim Biophys Acta. 2007; 1770:94-8. | Article I PubMed

33. Solanki K and Gupta MN. Optimizing biocatalyst design for obtaining high transesterification activity by a-chymotrypsin in non-aqueous media. Chem. Cent. J. 2008; 2:1-7. | Article

34. Majumder AB and Gupta MN. Increasing catalytic efficiency of Candida rugosa lipase for the synthesis of tert-alkyl butyrates in low water media. Biocatal. Biotrasform. 2011; 29:238.245. | Article

35. Partridge J, Hutcheon GA, Moore BD and Halling PJ. Exploiting hydration hysteresis for high activity of cross-linked subtilisin crystals in aceetonitrile. J. Am. Chem. Soc. 1996; 118:12873-12877. | Article

36. Khalaf N, Govardhan CP and Lalonde JJ. Cross-linked enzyme crystals as high active catalyst $\mathrm{s}$ in organic solvents. J. Am. Chem. Soc. 1996; 118:5494-5495. | Article

37. Wang YF, Yakovlevsky K and Margolin AL. An efficient synthesis of chiral amino acids and peptide alkylamides via clec subtilisin catalyzed coupling and situ resolution. Tetrahedron Lett. 1996; 37:5317-5320. Article

38. Pepin P and Lortie R. Influence of water activity on the enantioselective esterification of (R,S)-ibuprofen by crosslinked crystals of Candida antarctica lipase B in organic solvent media. Biotechnol Bioeng. 2001; 75:559-62. | Article | PubMed

39. Husain $Q$, Iqbal J and Saleemuddin M. Entrapment of concanavalin A-glycoenzyme complexes in calcium alginate gels. Biotechnol Bioeng. 1985; 27:1102-7. | Article | PubMed

40. Broun GB. Chemically aggregated enzymes. Methods Enzymol. 1976; 44:263-80. | Article | PubMed

41. Tyagi $R$, Batra R and Gupta MN. Amorphous enzyme aggregates: Stability toward heat and aqueous-organic cosolvent mixtures. Enzym. Microb. Technol. 1999; 24:348-354. | Article

42. Sheldon RA, Schoevaart R and Van Langen LM. Crosslinked enzyme aggregates (CLEAs): A novel and versatile method for enzyme immobilization (a review). Biocatal. Biotransform. 2005; 23:141-147. | Article

43. Gupta MN and Raghava S. Enzyme stabilization via cross-linked enzyme aggregates. In Minter SD (Ed.), Enzyme stabilization and immobilization 2011; 133-145. | Book

44. Lopez-Serrano P, Cao L, van Rantwijk F and Sheldon RA. Crosslinked enzyme aggregates with enhanced activity: application to lipases. Biotechnol. Lett. 2002; 24:1379-1383. | Article

45. Shah S, Sharma A and Gupta MN. Preparation of cross-linked enzyme aggregates by using bovine serum albumin as a proteic feeder. Anal Biochem. 2006; 351:207-13. | Article | PubMed 
Gupta et al. Universal Organic Chemistry 2013,

http://www.hoajonline.com/journals/pdf/2053-7670-1-1.pdf

doi: 10.7243/2053-7670-1-1

46. Cao L, van Rantwijk F and Sheldon RA. Cross-linked enzyme aggregates: a simple and effective method for the immobilization of penicillin acylase. Org Lett. 2000; 2:1361-4. | Article | PubMed

47. Cao L, van Langen LM, van Rantwijk F and Sheldon RA: Crosslinked aggregates of Penicillin acylase. Robust catalyst for the synthesis of ß-lactam antibiotics. J.Mol. Catal. B: Enzym. 2001; 11:665-670. | Article

48. van Langen LM, Selassa RP, van Rantwijk F and Sheldon RA. Cross-linked aggregates of (R)-oxynitrilase: a stable, recyclable biocatalyst for enantioselective hydrocyanation. Org Lett. 2005; 7:327-9. | Article | PubMed

49. Schoevaart R, Wolbers MW, Golubovic M, Ottens M, Kieboom AP, van Rantwijk F, van der Wielen LA and Sheldon RA. Preparation, optimization, and structures of cross-linked enzyme aggregates (CLEAs). Biotechnol Bioeng. 2004; 87:754-62. | Article | PubMed

50. Arsenault A, Cabana $\mathrm{H}$ and PeterJones J. Laccase-based CLEAs: Chitosan as a novel crosslinking agent. Enzym. Res. 2011; 2011:1-10. | Article

51. Winter KD, Soetaert $W$ and Desmet T. An imprinted crosslinked enzyme aggregate (iCLEA) of sucrose phosphorylase: Combining improved stability with altered specificity. Int. J. Mol. Sci. 2012; 13:11333-11342. | Article

52. Talekar S, Ghodake V, Ghotage T, Rathod P, Deshmukh P, Nadar S, Mulla $M$ and Ladole $M$. Novel magnetic cross-linked enzyme aggregates (magnetic CLEAs) of alpha amylase. Bioresour Technol. 2012; 123:542-7. | Article | PubMed

53. Gan Z, Zhang T, Liu Y and Wu D. Temperature-triggered enzyme immobilization and release based on cross-linked gelatin nanoparticles. PLoS One. 2012; 7:e47154. | Article | PubMed Abstract | PubMed Full $\underline{\text { Text }}$

54. Park TG and Hoffman AS. Effect of temperature cycling on the activity and productivity of immobilized beta-galactosidase in a thermally reversible hydrogel bead reactor. Appl Biochem Biotechnol. 1988; 19:19. | Article | PubMed

55. Kreiner M, Moore BD and Parkar MC. Enzyme-coated micro-crystals: a 1-step method for high activity biocatalyst preparation. Chem. Commun. 2001; 12:1096-1097. | Article

56. O'Farrell N, Kreiner M, Moore BD and Parker MC. A rapid and direct method for the determination of active site accessibility in proteins based on ESI-MS and active site titrations. Biotechnol Bioeng. 2006; 95:767-71. | Article | PubMed

57. Kreiner M, Fuglevand G, Moore BD and Parker MC. DNA-coated microcrystals. Chem Commun (Camb). 2005; 2675-6. I Article I PubMed

58. Shah S, Sharma A, Varandani D, Mehta B and Gupta MN. A high performance lipase preparation: characterization and atomic force microscopy. J Nanosci Nanotechnol. 2007; 7:2157-60. | Article | PubMed

59. Kreiner M and Parker MC. High-activity biocatalysts in organic media: solid-state buffers as the immobilisation matrix for protein-coated microcrystals. Biotechnol Bioeng. 2004; 87:24-33. I Article I PubMed

60. Shah S, Sharma A and Gupta MN. Cross-linked protein-coated microcrystals as biocatalysts in non-aqueous solvents. Biocatal. Biotransform. 2008; 26:266-271. I Article

61. Yan J, Yan Y, Liu S, Hu J and Wang G. Preparation of cross-linked lipasecoated micro-crystals for biodiesel production from waste cooking oil. Bioresour Technol. 2011; 102:4755-8. | Article | PubMed

62. Solanki K and Gupta MN. A chemically modified lipase preparation for catalyzing the transesterification reaction in even highly polar organic solvents. Bioorg Med Chem Lett. 2011; 21:2934-6. | Article | PubMed

63. Lovrein RE, Goldensoph C, Anderson P and Odegard B. Three phase partitioning via t-butanol: enzymes preparation from crudes. In Burgess $\mathrm{R}(\mathrm{Ed})$, Protein purifcaton: micro to macro 1987, 521-553. | Pdf

64. Roy I, Sharma A and Gupta MN. Obtaining higher transesterification rates with subtilisin Carlsberg in nonaqueous media. Bioorg Med Chem Lett. 2004; 14:887-9. | Article I PubMed

65. Gupta MN and Roy I. Enzymes in organic media. Forms, functions and applications. Eur J Biochem. 2004; 271:2575-83. | Article I PubMed

66. Gupta MN. Enzyme function in organic solvents. Eur J Biochem. 1992;
203:25-32. | Article | PubMed

67. Singh RK, Gourinath S, Sharma S, Roy I, Gupta MN, Betzel C, Srinivasan $A$ and Singh TP. Enhancement of enzyme activity through three-phase partitioning: crystal structure of a modified serine proteinase at $1.5 \mathrm{~A}$ resolution. Protein Eng. 2001; 14:307-13. | Article | PubMed

68. Rather GM, Mukherjee J, Halling PJ and Gupta MN. Activation of Alpha Chymotrypsin by Three Phase Partitioning Is Accompanied by Aggregation. PLOS ONE. 2012; 7:e49241. I Article

69. Hult $\mathrm{K}$ and Berglund P. Enzyme promiscuity: mechanism and applications. Trends Biotechnol. 2007; 25:231-8. | Article | PubMed

70. Busto E, Gotor-Fernandez V and Gotor V. Hydrolases: catalytically promiscuous enzymes for non-conventional reactions in organic synthesis. Chem Soc Rev. 2010; 39:4504-23. | Article I PubMed

71. Li C, Feng XW, Zhou YJ and Yu XQ. Biocatalytic promiscuity: The first lipase-catalysed assymetric aldol reaction. Green Chem. 2008; 10:616618. | Article

72. Majumder AB, Ramesh NG and Gupta MN. A lipase catalysed reacton wth a tricyclic diketone: yet another example of biocatalytic promiscuity. Tetrahedron Lett. 2009; 50:5190-5193. | Article

73. Cai Y, Yao SP, Wu Q and Ln XF. Michael addition of midazole with acrylates catalysed by alkaline protease from Bacillus subtilis $\mathbf{n}$ organic media. Biotechnol. Lett. 2004; 26:525-528. | Article

74. Cai Y, Wu Q, Xiao YM, Lv DS and Lin XF. Hydrolase catalysed Michael addition of imidazoles to acrylic monomers in organic media. J. Biotechnol. 2004; 121:330-337. I Article

75. Liu B, Qian X, Wu Q and Lin X. Two lipase catalysed sequential synthesis of drug derivatives $\mathbf{n}$ organic media. Enzym. Microb. Technol. 2008; 43:375-380. | Article

76. Priego J, Ortz-Nava C, Carrillo-Morales M, Lopez-Munguia A, Escalante $J$ and Castillo E. Solvent engineering: An effective tool to direct chemoselectvity in a lipase-catalysed Michael addition. Tetrahedron 2009; 65:536-539. I Article

77. Qian C, Xu J, Wu Q, Lv D and Lin X. Promiscuous acylase-catalysed aza-Michael additions of aromatic $\mathbf{N}$-heterocycles in organic solvent. Tetrahedron Lett. 2007; 48:6100-6104. I Article

78. Wu WB, Wang N, Xu JM, Wu Q and Lin XF. Penicillin G acylase catalyzed Markovnikov addition of allopurinol to vinyl ester. Chem Commun (Camb). 2005; 2348-50. I Article I PubMed

79. Torre O, Alfonso I and Gotor V. Lipase catalysed Michael addition of secondary amines to acrylonitrile. Chem Commun (Camb). 2004; 1724-5. | Article | PubMed

80. Lou FW, Liu BK, Wu Q, Lv DS and Lin XF. Candida Antarctica lipase (CALB)-catalysed carbon-sulphur bond addition and controllable selectivity in organic media. Adv. Synth. Catal. 2008; 350:1959-1962. I Article

81. Carboni-Oerlemans C, Dominguez de Maria P, Tuin B, Bargeman G, van der Meer A and van Gemert R. Hydrolase-catalysed synthesis of peroxycarboxylic acids: Biocatalytic promiscuity for practical applications. J Biotechnol. 2006; 126:140-51. | Article | PubMed

82. Yadav GD and Devi KM. Enzymatic synthesis of perlauric acid using Novozym 435. Biochem. Eng. J. 2002; 10:93-101. | Article

83. Gupta MN, Kaloti M, Kapoor M and Solanki K. Nanomaterials as matrices for enzyme immobilization. Artif Cells Blood Substit Immobil Biotechnol. 2011; 39:98-109. | Article | PubMed

84. Vertegel AA, Siegel RW and Dordick JS. Silica nanoparticle size influences the structure and enzymatic activity of adsorbed lysozyme. Langmuir. 2004; 20:6800-7. | Article | PubMed

85. Shah S, Solanki K and Gupta MN. Enhancement of lipase activity in non-aqueous media upon immobilization on multi-walled carbon nanotubes. Chem. Cent. J. 2007; 1:30-35. | Article

86. Asuri P, Bale SS, Karajanagi SS and Kane RS. The protein-nanomaterial interface. Curr Opin Biotechnol. 2006; 17:562-8. I Article I PubMed

87. Chen YZ, Yang CT, Ching CB and Xu R. Immobilization of lipases on hydrophobilized zirconia nanoparticles: highly enantioselective and reusable biocatalysts. Langmuir. 2008; 24:8877-84. | Article | PubMed 
Gupta et al. Universal Organic Chemistry 2013,

http://www.hoajonline.com/journals/pdf/2053-7670-1-1.pdf

88. Solanki K and Gupta MN. Simultaneous purification and immobilization of Candida rugosa lipase on superparamagnetic $\mathrm{Fe}_{3} \mathrm{O}_{4}$ nanoparticles for catalyzing transesterification reactions. New J Chem. 2011; 35:2551-

2556. | Article

89. Straathof AJJ and Adlercreutz P (Eds). Applied Biocatalysis. 2000. | Book

90. Schoemaker HE, Mink D and Wubbolts MG. Dispelling the myths--

biocatalysis in industrial synthesis. Science. 2003; 299:1694-7. | Article

I PubMed

\section{Citation:}

Gupta MN, Mukherjee J and Malhotra D. Use of high activity enzyme preparations in neat organic solvents for organic synthesis. Univers Org Chem. 2013; 1:1. http://dx.doi.org/10.7243/2053-7670-1-1 